\title{
Multidimensional Land-use Information for Local Planning and Land Re- sources Assessment in Indonesia: Classification Scheme for Information Extraction from High-Spatial Resolution Imagery
}

\author{
Projo Danoedoro \\ Remote Sensing Laboratory, Faculty of Geography, Universitas Gadjah Mada, Indonesia
}

Received: 2018-08-10 Accepted: 2019-03-28

Keywords:
land-use;
multidimensional classification
system;
remote sensing;
high-spatial;
resolution.

Corespondent Email: projo.danoedoro@geo.ugm.ac.id

\begin{abstract}
Suitable land-cover/land-use information is rarely available in most developing countries, particularly when newness, accuracy, relevance, and compatibility are used as evaluation criteria. In Indonesia, various institutions developed their own maps with considerable differences in classification schemes, data sources and scales, as well as in survey methods. Redundant land-cover/land-use surveys of the same area are frequently carried out to ensure the data contains relevant information. To overcome this problem, a multidimensional land-use classification system was developed. The system uses satellite imagery as main data source, with a multi-dimensional approach to link land-cover information to land-use-related categories. The land-cover/land-use layers represent image-based land-cover (spectral), spatial, temporal, ecological and socio-economic dimensions. The final land-cover/land-use database can be used to derive a map with specific content relevant to particular planning tasks. Methods for mapping each dimension are described in this paper, with examples using Quickbird satellite imagery covering a small part the Semarang area, Indonesia. The approaches and methods used in this study may be applied to other countries having characteristics similar to those of Indonesia.
\end{abstract}

\section{Introduction}

Limited availability of land-cover/land-use information for planning and land resource assessment is a common issue in many developing countries. The problem comes up when newness, accuracy, relevance, and compatibility are used as the main criteria for selecting spatial data to support those activities. Indonesia is an example where land-use information is developed by various institutions with overlapping authorities and non-systematic means of updating. These may lead to redundancy in the production of land-cover/land-use maps that are incompatible with each other and cannot be used as a common reference by various planning-related institutions. With regard to this problem, development of a land-cover/land-use classification system that can accommodate different needs of various physical planning and biophysical applications, but uses a common and consistent base, is a necessity.

Efforts in developing standards for land-cover/ land-use classification system have been carried out by various national and international institutes. At global levels, for example, Loveland and Belward (1997) developed a classification scheme with 17 classes to map actual land-cover of the global land surface based on multitemporal global area coverage (GAC) of NOAAAVHRR datasets. More recent efforts at global level have been done by many authors, including, McCallum et al. (2010), Hansen et al. (2013), Latham et al. (2014) and Hengl (2017). At regional levels, annual land cover classification based on MODIS has been demonstrated by Tchuente et al. (2010) and Cord et al. (2010) using Terra ASTER. At local levels, Pu et al. (2011) have undetaken a detailed land-cover classification using Ikonos.

The most popular scheme was developed by the United States Geological Survey long time ago (Anderson et al., 1976), which is multilevel in character. However, this system has been criticised due to its resource-oriented approach as compared to the Standard Land-Use Coding Manual (Jensen, 2013). On the other hand, van der Ploeg et al. (2010) developed classification scheme focusing on agriculture-oriented land-use categorisation with special emphasis on spatio-temporal aspects, although they did not explain the remote sensing and GIS methods for mapping the specified categories. As the USGS classification scheme tends to mix up the land-cover and land-use concepts, van Gils et al. (1991) tried to separate land-cover from land-use categories and simultaneously established relations between the two.

Other classification systems have also taken land-cover/land-use differences into consideration. Such classification systems were developed by several authors, e.g. Young (1998) and Janssen and Di Gregorio 
(2003). Young's classification system was purposively developed to describe the modification level of the land by human activities, so that it might suitable for landresource based or agricultural planning, but not for other purposes. An example on how remotely sensed data-derived land-cover classes are converted to landuse categories was given by Lee et al. (2009) using Landsat TM at 1:200,000 scale. However, their work was underlain by an assumption that there is no widely accepted methodology in remote sensing and other spatial analysis systems to describe and characterise land-use, particularly the one for facilitating data collection and assuring data harmonisation between datasets in a country and between countries.

The aforementioned classification systems show similarities in the use of single attributes for describing the mapping units. There is also a lack of description of the methods for generating the information using digital imagery. The classification procedures in the previously mentioned classification systems rely heavily on the visual interpretation of remotely sensed imagery. It is important to note that the criteria used in the USGS classification system were developed more than 30 years ago, prior to multi-scale satellite imagery and image processing techniques of today (Lillesand et al., 2014). As the computer-based methods for information extraction offer advantages over the visual interpretation, development of classification systems that accommodate the use of both digital and visual approaches are essential. Moreover, many examples were carried out using moderate-spatial resolution images, so that complexities in automatic digital classification were rarely found.

The use of image processing and/or GIS methods for generating land-cover or land-use maps have been demonstrated by several authors, for example, the studies of Szuster et al. (2011) and Kallimanis and Koutsias (2013). Analysis of high-spatial resolution imagery like Quickbird was also carried out in by Zhang and Zhu (2011) who used spectral features, texture features obtained from the gray-level co-occurrence matrix, and shape features. The study of Kindu et al. (2013) demonstrated object-based image analysis approach (OBIA/GEOBIA) for land-cover/land-use mapping. However, the aforementioned studies did not differentiate the land-cover from land-use concepts.

Effort in harmonising land-cover classification system (LCCS) with habitat general categories (HGC, which is more ecology-oriented) was undertaken by Kosmidou et al. (2014). Moreover, several authors showed computer-based analyses that clearly differentiated land-cover and land-use concepts. For example, Feng and Flewelling (2004) assessed semantic similarity between land-cover and land-use classes. They found that semantic interoperability between classification schemes is very important. This finding is in line with the study of Feranec et al. (2014). A useful method for converting land-cover data to land- use information based on image analysis was proposed by Martinez and Mollicone (2012), who worked using high-spatial resolution imagery and introduced an identification of 'key land elements' characterising land-use classes.

The main objective of this study was to develop an image-based land use information system, which is versatile in character, to support local planning and land resources assessment tasks at a variety of spatial scales in Indonesia. Based on this objective, three goals were established, i.e. (1) a multidimensional landuse classification scheme, (2) information extraction methods using high-spatial resolution imagery with Quickbird as an example, and (3) accuracy assessment of the derived maps.

\section{The Methods}

General land-cover classes are normally broken down into more detailed categories. The use of single attributes of land-cover/land-use at subtler levels tends to increase incompatibilities between schemes. Thus, for a local region partly covered by adjoining landcover/land-use map sheets with different classification schemes, it would be more difficult to undertake environmental analyses and planning based on the same understanding of the data. Multiple attributes of landcover/land-use in a single map layer might be generated using the land or landscape ecological approach (Lee et al. 2009), by which all attributes fall within exactly the same mapping unit boundaries. This approach tries to integrate information on terrain/land characteristics with the land-cover features appearing on the imagery. By doing so, land-use information and even subtler land-cover types, e.g. eco-floristic composition of vegetation, can be derived. However, multispectral classification of digital imagery can only derive landcover-related spectral classes. The tentative categories can then be regrouped and re-labeled into more meaningful land-cover classes. Derivation of subtler information on land-cover/land-use through per-pixel image classification can also be done with contextual information, such as landscape characteristics related to soil properties and slope steepness, which have been explored by Ehlers et al. (2003) and Danoedoro (2003).

Development of land-cover/land-use classification systems for local planning should make use of highspatial resolution imagery, in order to understand its potentials and limitation for supporting multipurpose land-cover/land-use surveys at relatively large scales. This study is also expected to complement previous research dealing with high-spatial resolution images, which concentrated on particular aspects of processing, e.g. textural approach (Puissant et al., 2005), and objectbased image analysis/OBIA (Moreno and de Larriva, 2012; Kallimanis and Koutsias, 2013). Therefore, development of the classification systems should be carried out in response to the availability of remotely sensed imagery and its analysis systems. 


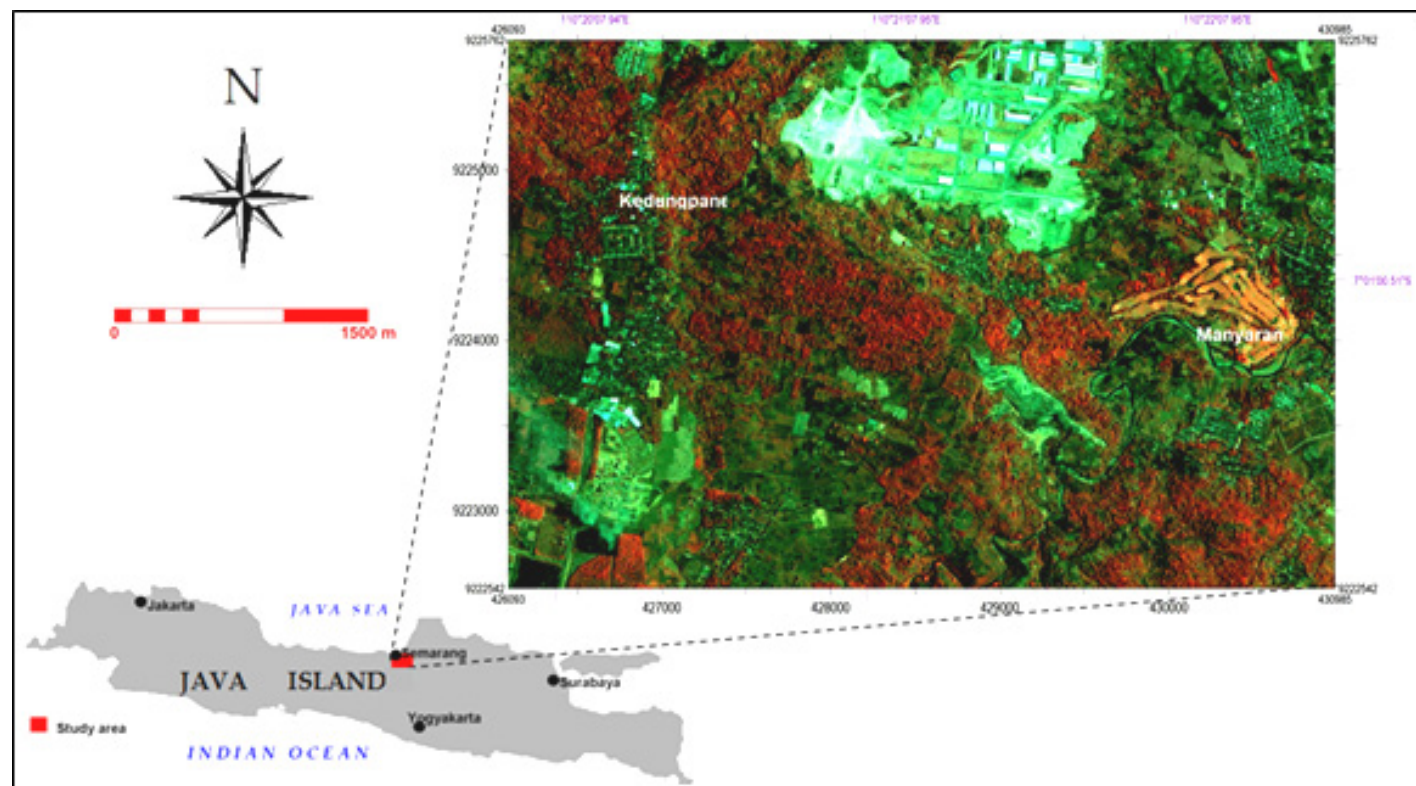

Figure 1. The study area in Semarang, Central Java, Indonesia as shown in Quickbird image.

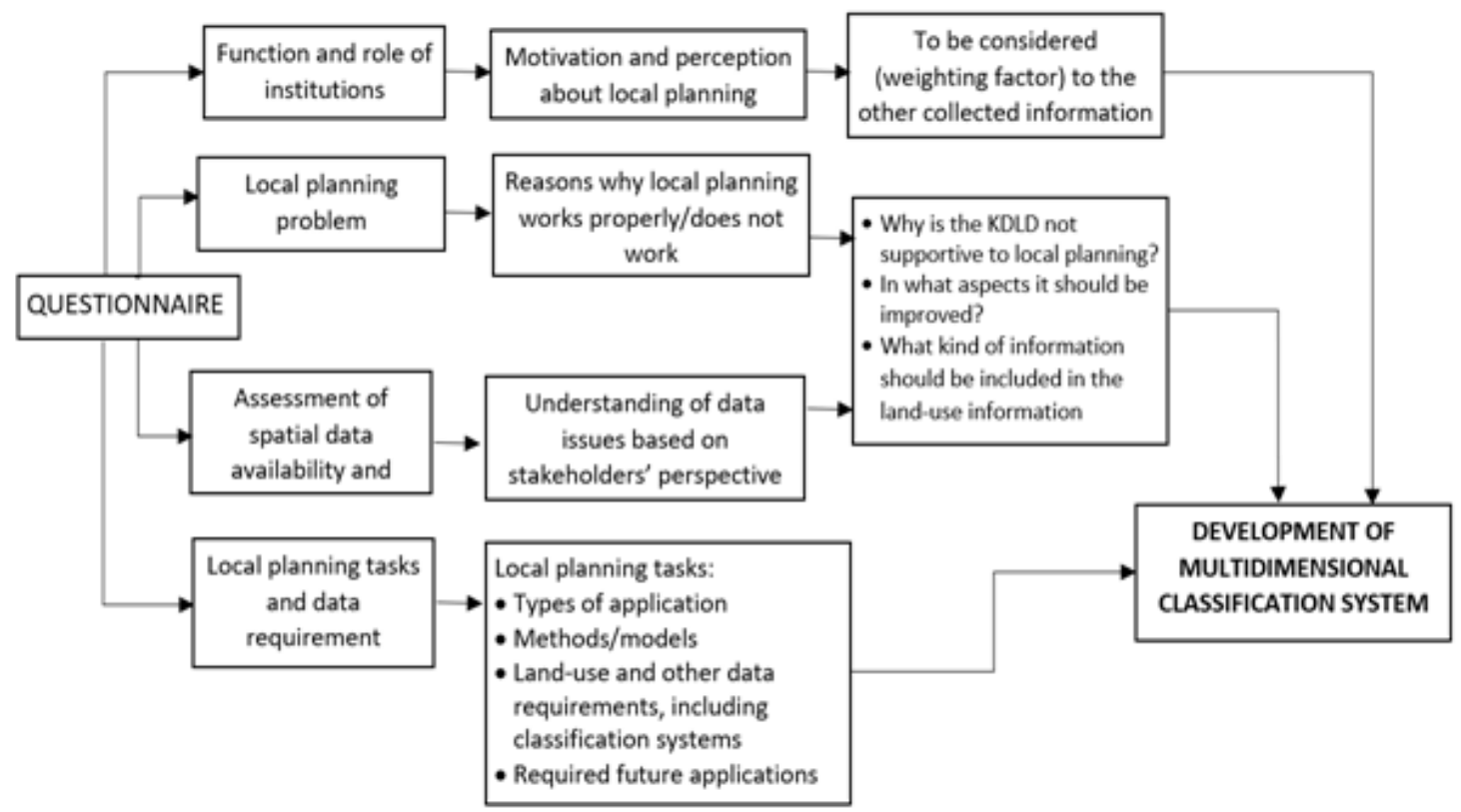

Figure 2. Method of classification scheme development.

This study used Quickbird multispectral imagery at $2.4 \mathrm{~m}$ (multispectral) spatial resolutions. The image dataset was recorded on 28 June 2006 and has been preprocessed to a standard product, both radiometrically and geometrically, and projected into UTM coordinate system. A topographic map sheet of Bakosurtanal (Indonesian National Coordinating Agency for Surveys and Mapping, now Geospatial Information Agency) at scale of 1:25,000 was also used in conjunction with panchromatic aerial photographs at scale of 1:10,000, to characterise the larger spatial context of the area. In order to process the image data, ENVI 4.5 were used for image processing and ILWIS 3.4 Open was used for further data analysis in a raster GIS data environment.

This study consisted of two activities, i.e. (1) establishment of classification scheme, and (2) development of land-cover/land-use information extraction methods and accuracy assessment. In order to establish a classification scheme that can accommodate a range of environmental applications related to local planning tasks, the author interviewed 36 stakeholders of the study area comprising government and non-government groups using questionnaires. In addition, several land-cover/land-use classification schemes used in Indonesia, and associated application models requiring land-cover/land-use information were collected and analysed, e.g. soil loss model using USLE/Universal Soil Loss Equation (Sulistyo et al.,2017). Based on the newly constructed classification scheme, the land-cover/land-use information extraction methods were developed and applied by combining spectral classification, visual (on-screen) interpretation, 
Table 1. Description of each land-use dimension used in this study.

\begin{tabular}{|c|c|c|}
\hline LAND-USE DIMENSION & Symbol Prefix & DESCRIPTION \\
\hline Spectral-related cover & $\mathrm{C}$ & $\begin{array}{l}\text { Expressed as land-cover types, which can be identified } \\
\text { using spectral analysis and classification }\end{array}$ \\
\hline Spatial & S & $\begin{array}{l}\text { Expressed as shapes, spatial arrangement or pattern, } \\
\text { geographical position, which serve as additional key } \\
\text { elements to distinguish objects }\end{array}$ \\
\hline Temporal & $\mathrm{T}$ & $\begin{array}{l}\text { Related to permanent, temporal or seasonal changes, } \\
\text { e.g. length of inundation, pruning and crop rotation, } \\
\text { growing period, soil tillage or land development stage. } \\
\text { Information related to spectral and spatial aspects is } \\
\text { also required to determine temporal dimension }\end{array}$ \\
\hline Ecological & $\mathrm{E}$ & $\begin{array}{l}\text { Land-cover and land-use types express interaction } \\
\text { between vegetation, animals and human activities } \\
\text { with the land where they exist. Their existences also } \\
\text { represent the environmental characteristics of the area } \\
\text { as habitats, e.g. mangrove formation, upland agricul- } \\
\text { ture, slum areas }\end{array}$ \\
\hline Socio-economic function & $\mathrm{F}$ & $\begin{array}{l}\text { Expresses how people make use of the land to satisfy } \\
\text { some of their needs. The socio-economic function } \\
\text { expresses the land-use. }\end{array}$ \\
\hline Political/legal & $\mathrm{P}$ & $\begin{array}{l}\text { Invisible boundaries in general. Basically difficult } \\
\text { to extract using remotely sensed imagery except the } \\
\text { boundaries coincide with the physical ones. It is not } \\
\text { included in the mapping process. }\end{array}$ \\
\hline
\end{tabular}

OBIA and knowledge-based image classification in a raster GIS environment.

\section{Establishment of Classification Scheme}

Since this multidimensional classification scheme was intended to accommodate various purposes, we also call it as versatile land-use classification system. Method for developing of the land-cover/land-use classification scheme is described in Figure 2. Based on this procedure, a conceptual framework of land-cover/ land-use information was then established. In this framework, land-cover and land-use are considered as separate concepts, even though they are closely related.

As viewed from remote sensing perspective, landcover/land-use information can be broken down into C (spectral-related cover), S (spatial), T (temporal), $\mathrm{E}$ (ecological), $\mathrm{F}$ (socio-economic function) and $\mathrm{P}$ (political/legal) dimensions. A brief description of each dimension is presented in Table 1. Among them, only the political/legal dimension is considered impossible to extract from remotely sensed imagery, unless the object boundaries exactly coincide with their physical features on the images. The $\mathrm{C}, \mathrm{S}$ and $\mathrm{T}$ dimensions are closer to the land-cover concept, since they are based on surface cover and there is no description of how people make use of the land. The dimension of $\mathrm{F}$, on the other hand, is based on how people make use of the land (land-use), irrespective of cover types. While the E dimension gives emphasis to the ecological context of the features being mapped, it may occasionally reflect land-use when it deals with areas having strong human influences. Table 1 describes these dimensions.

According to this classification system, all dimensions should be expressed in separate map layers showing the spatial distribution of spectral-related cover, spatial structure, temporal aspects, ecological units, and socio-economic function of the land-use. These five data layers are stored together in a versatile land-use dataset, ready for data retrieval through spatial queries in a GIS environment.

\section{Information Extraction Methods for Each Dimension \\ Information extraction methods for each} dimension may vary from level to level and from one dimension to another. Advances in remote sensing and image processing offer numerous methods and techniques for generating thematic information. From a practical point of view, it should be noted that more advanced techniques do not always generate more accurate results. This paper concentrates on methods which have proven to be successful for deriving thematic information, such as standard multispectral classification explained in Jensen (2013).

The author performed supervised classification for generating land-cover/land-use data in terms of spectral-related dimension, while visual interpretation and/or OBIA (Tarantino et al., 2011; and Moskal et al., 2011) was applied for deriving spatial dimension. Two types of spectral classification were chosen, i.e. 


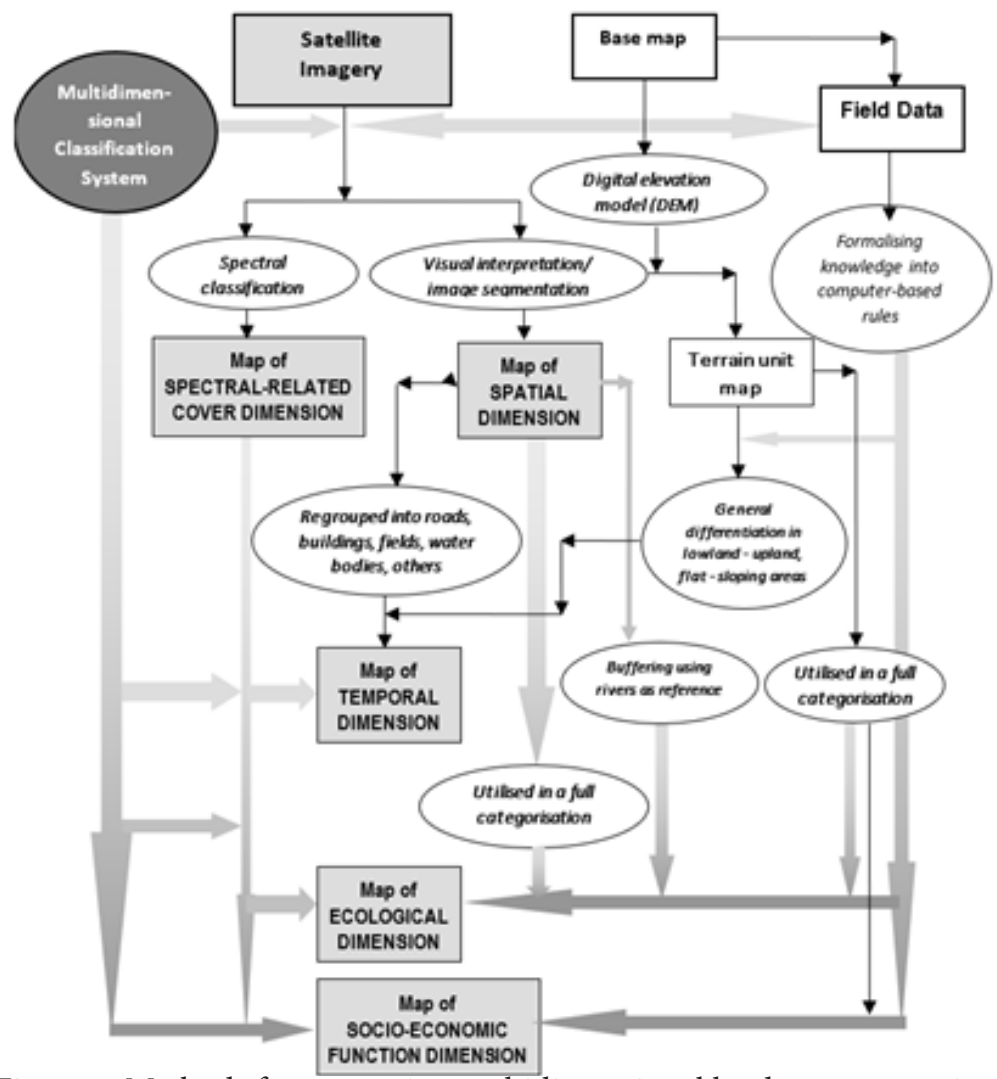

Figure 3. Methods for generating multidimensional land-use maps using Danoedoro (2007) approach.

standard multispectral classification using maximum likelihood algorithm and multispectral classification using combination of texturally transformed and original bands (Puissant et al.,2004; Danoedoro and Phinn, 2005). Since the number of classes to be produced is quite large, a careful sampling procedure assisted by Jeffries-Matusita separability index computation (Danoedoro et al., 2004) was also carried out during the sampling procedure.

As shown in Figure 3, spatial information extraction was carried out using visual interpretation through onscreen digitisation and OBIA. The OBIA made use of image segmentation approach according to Eastman (2016), which takes into account (a) the window size for creating variance-based boundaries, (b) weight of every input band, (c) similarity tolerance, and (d) the weights for mean as well as for variance factors. The segments were used as a basis for sampling procedure, so that the statistical signatures of the sampled segments were developed. Sample names were given with respect to the spatial dimension categorisation. After that, a standard classification followed to generate per-pixel classification result. Classification of the segments was applied by combining the per-pixel approach and the segments using majority rules. The on-screen digitisation was performed using Quickbird pan-sharpened true and false colour composites as backdrop images.

The multispectral classification and visual interpretation directly delivered information related to cover types and their spatial structure. Contrarily, the temporal, ecological and socio-economic dimensions require more complex information such as date and season of recording, terrain characteristics, geographical site and association. By combining the 'basic' information (in terms of spectral-related cover and spatial dimension maps) and other data, maps of other dimensions could be generated. A geomorphological approach described by van Zuidam and van ZuidamCancellado (1983) was applied in order to generate the terrain unit map, assuming that every mapping unit represents a set of physical land characteristics.

This study assumed that temporal pattern, ecological context, and socio-economic function of land-cover categories correlate to the corresponding cover types, their land characteristics, their condition/status at the time of recording, geographical site and association, as well as their spatial patterns. Each dimension is constituted by unique combinations between those aforementioned factors. By understanding the relationships between variables through field data collection and analyses, a set of knowledge-based rules were developed under a raster-based GIS in order to derive the maps of temporal, ecological and socioeconomic dimensions.

Information on temporal dimension of landuse was generated by integrating the land-cover map (representing the spectral-related cover dimension), 


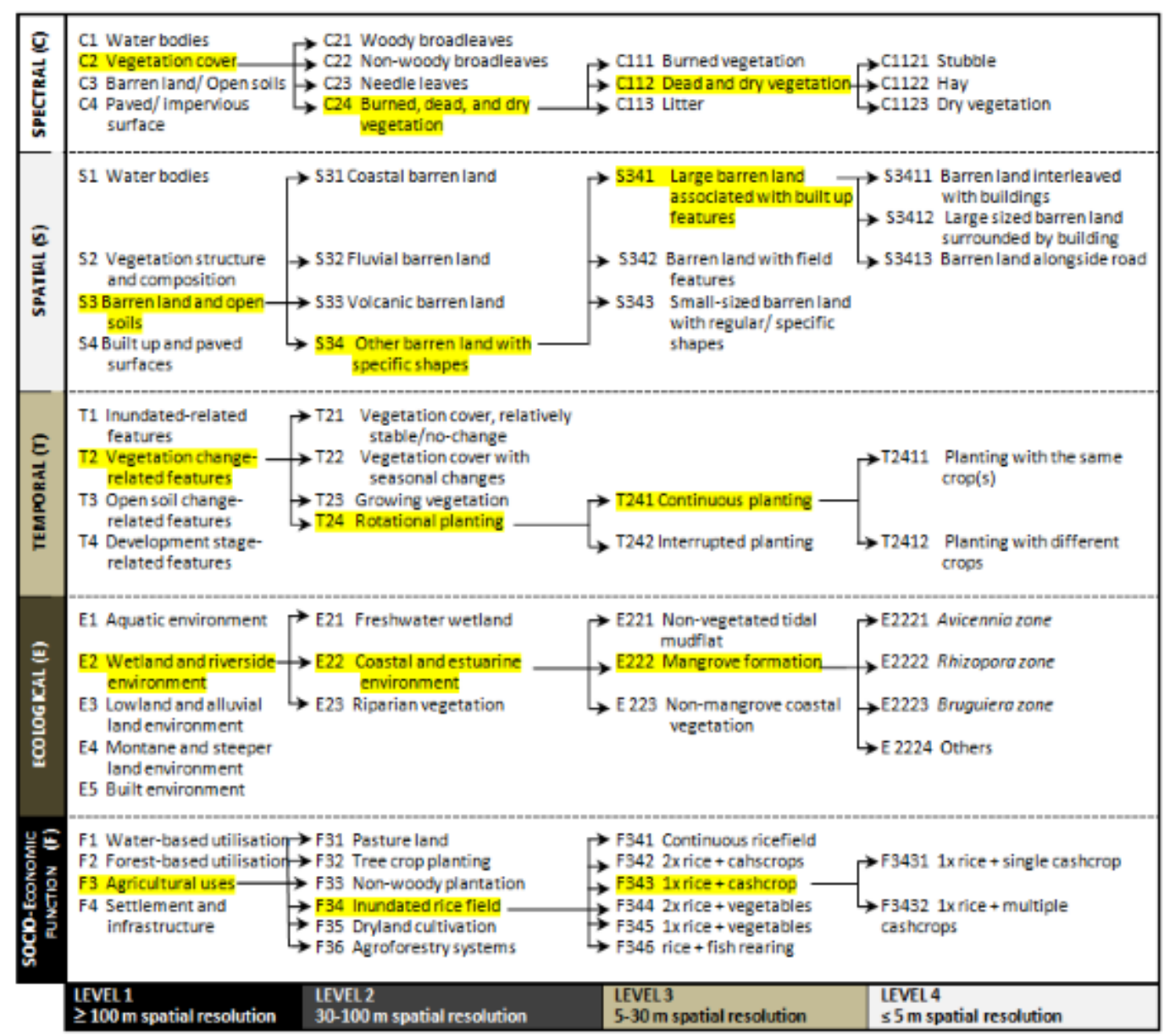

Figure 4. Example of categorisation in the multi-dimensional land-use classification scheme.

spatial dimension map, terrain map derived from the DEM of the study area, and information on date and season of recording. To do so, the spatial dimension map was converted to raster format. The DEM was also converted to elevation and relief/topographic zones. Once the input maps are stored in raster format, a set of rule-based map overlay operations could be run.

The ecological categorisation of land-cover/landuse was developed with respect to the categorisation of tropical ecosystem types (Osborne, 1999), as well as human settlement-related ecosystems as viewed from a human ecological perspective (Pearlman and Milder, 2005). Operationally, categorisation under the ecological dimension was based on the following variables: (a) spectral-related cover types, (b) spatial structure of the cover defined under spatial dimension, (c) temporal characteristics of the cover under temporal dimension, (d) land characteristics of the area (e.g. climate, rainfall, elevation, landform, soil texture, slope steepness, surface drainage, water availability) represented by the terrain units, and (e) other factors affecting the existence of any mapable environment such as buffer area for riparian vegetation.

The socio-economic function is the only dimension showing information on the use of the land, regardless the cover types exist (Danoedoro, 2006). Maps of spectral-related cover and spatial dimensions were used as the main input to generate information on socioeconomic function of the land-cover/land-use. Since different socio-economic functions can be composed by the same combination of spectral-related cover class and spatial dimension category, other spatial data should be used, e.g. terrain characteristics in terms of terrain/ landform map, buffer map, and temporal dimension map. All maps were integrated in a rulebased overlay process, controlled by the knowledge about relationship between land-cover, land-use, and landscape characteristics obtained from the field and references.

\section{Results and Discussion}

\section{The Classification Scheme}

A multidimensional classification scheme has been developed, as illustrated in Figure 4. This classification system can be considered as the first versatile multidimensional land-use information system. Its versatility is defined by a set of flexible, open-ended, and relatively easy-to-translate classification schemes, because it systematically contains a range of attributes required by various applications. All categories were developed using image-based mapping approaches.

The spectral-related cover and spatial dimensions (C and S) show a similar pattern in grouping features related to general land-cover types, i.e. water, vegetation, 
Indonesian Journal of Geography, Vol. 51 No. 2, August 2019 : 131 - 146

Table 2. Number of samples for accuracy assessment

\begin{tabular}{lrrrr}
\hline Land-use Dimension & $\begin{array}{l}\text { Image/map } \\
\text { dimension } \\
\text { (pixels) }\end{array}$ & $\begin{array}{l}\text { Nr.of Classes } \\
\text { obtained }\end{array}$ & $\begin{array}{l}\text { Number of validator } \\
\text { samples (polygons) }\end{array}$ & $\begin{array}{l}\text { Number of pixels involved } \\
\text { in validation }\end{array}$ \\
\hline Spectral dimension & $2000 \times 1200$ & 40 & 160 & 24,324 pixels \\
Temporal dimension & $2000 \times 1200$ & 26 & 104 & 14,215 pixels \\
Ecological dimension & $2000 \times 1200$ & 30 & 120 & 14,701 pixels \\
$\begin{array}{l}\text { Socio-economic func- } \\
\text { tion dimension }\end{array}$ & $2000 \times 1200$ & 28 & 112 & 26,436 pixels \\
\end{tabular}

Table 3. Overall accuracy assessment of multidimensional land-use maps. Kappa index is presented in brackets

\begin{tabular}{llllll}
\hline & $\begin{array}{l}\text { Spectral-related } \\
\text { cover }\end{array}$ & Spatial & Temporal & Ecological & $\begin{array}{l}\text { Socio-economic } \\
\text { function }\end{array}$ \\
\hline Overall accuracy & $85.90 \%$ & no & $91.09 \%$ & $82.09 \%$ & $86.00 \%$ \\
Kappa & $(0.8539)$ & assessment $^{*}$ & $(0.8878)$ & $(0.8024)$ & $(0.8382)$ \\
\hline
\end{tabular}

${ }^{*}$ See explanation in sub-section 4.2.3.

barren land/open soils, and building/impervious surfaces. Categorisation under the temporal dimension (T) reflects a similar pattern to that shown by the spectral-related cover and spatial dimensions, even though it gives emphasis on the changes of the features. The other two, E and F, show different grouping as they do not express land-cover types.

Level I, which is designed for maps at scale of 1:1,000,000 or coarser, shows a great similarity between spectral-related cover and spatial dimensions. Both dimensions use water bodies, vegetation cover/ vegetation structure and composition, barren land/ open soils, and built up/paved impervious surfaces. This means that there is no need to distinguish land cover-related objects with respect to their spatial structure at very small scales. At the same level, the temporal categorisation also describes the features in very general way, which is basically the same as the previously discussed dimensions

On the other hand, the ecological and socioeconomic function dimensions at level I define their categories in different ways. There are five major categories under ecological dimension, namely: (a) E1/aquatic environment, (b) E2/wetland and riverside environment, (c) E3/lowland and alluvial environment, (d) E4/montane and steeper lands environment, and (e) E5/built environment. The socio-economic function dimension has the following major categories: (a) F1/ water-based utilisation, (b) F2/forest-based utilisation, (c) F3/agricultural uses, and (d) F4/settlement and infrastructures.

\section{The Multidimensional Land-use Mapping}

This section discusses the resultant maps representing spectral-related cover, spatial, temporal, ecological and socio-economic dimensions of
LU. Accuracy assessment of the resultant maps is summarised in Table 2.

\section{Accuracy Assessment}

The accuracy assessment was carried out for spectral, temporal, ecological, and socio-economic function dimensions, since they can be validated using field-based observation. On the other hand, the spatial dimension at the defined spatial resolution $(2.4 \mathrm{~m})$ could not be applied due to the fact that the specified categories referred to spatial dimension are easier to observe and measure using vertical top-down image, instead of horizontal field observation.

Samples for accuracy assessment were taken using stratified random sampling strategy, by which the number of samples was specified referring to Danoedoro (2015), and they are selected in terms of polygons. The number of polygons were proportionally distributed with respect to the number of classes, and then they were transformed into pixels, to be overlain with the classification results. A total number of 79,676 pixels of validator samples were involved, distributed into 496 polygons, as shown in Table 2.

The overlay process generated confusion matrix, which then could be computed as overall accuracy and Kappa. Appendix 1 shows an accuracy assessment example of temporal dimension map. The other maps were treated in the same way, resulted summary of accuracy assessment as shown in Table 3.

\section{Map of Spectral-related Cover Dimension}

The spectral-related cover dimension was derived using multispectral classification. A separability index measuring spectral separability between samples (e.g. using Jeffries-Matusita index computation), described in Jensen (2013) was run while the spectral sampling is in progress. By doing so, the result can be guided to a relatively accurate classification. An overall 


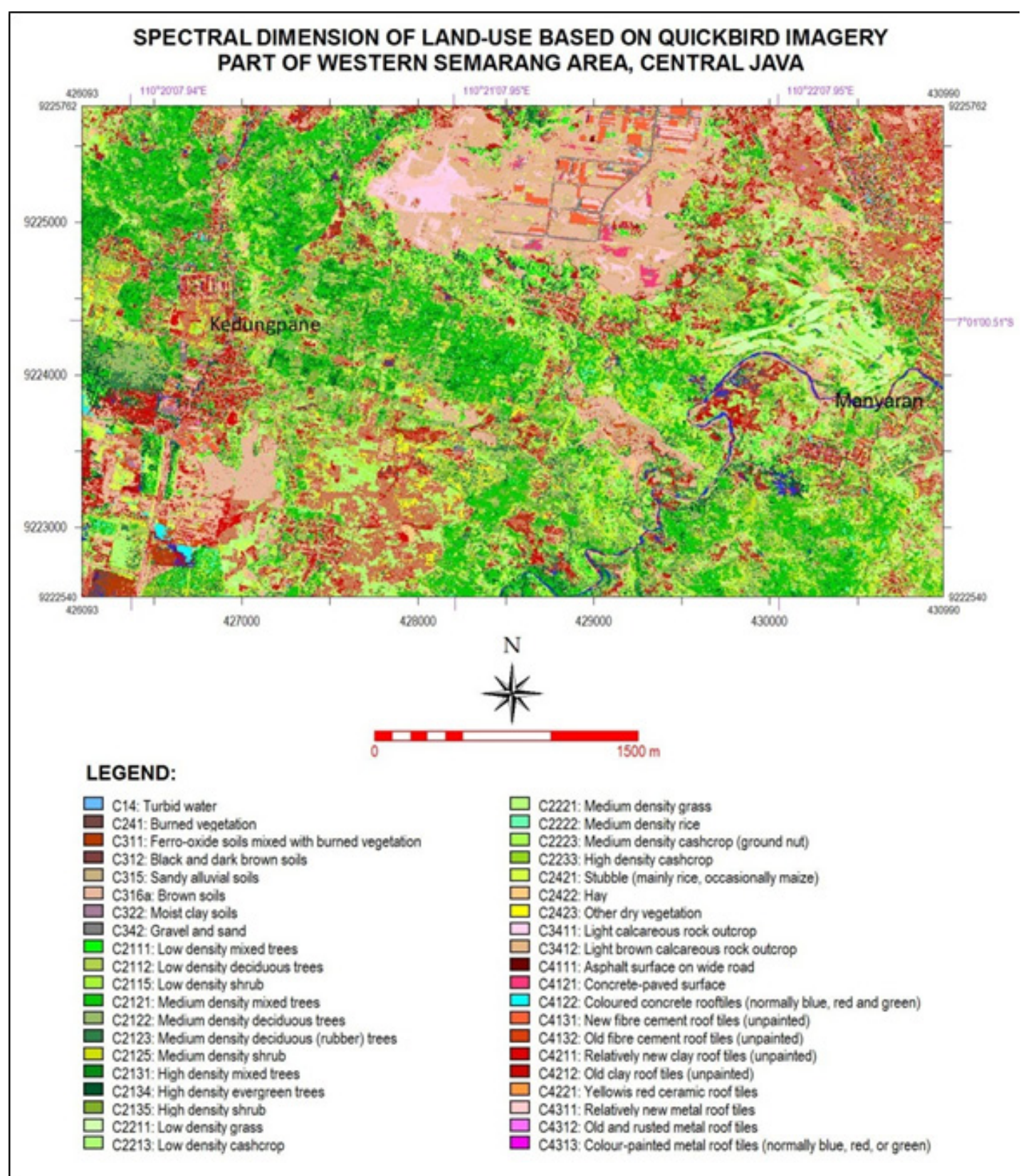

Figure 5. Map of spectral dimension of land-use.

classification accuracy level of $79.02 \%$ was achieved using Quickbird imagery.

In comparison to Landsat ETM+ imagery-based results achieved by Danoedoro and Phinn (2005), the Quickbird's were less accurate. It is common for higher spatial resolution image, since per pixelbased classification algorithms often are not capable of extracting desired information from such higherspatial resolution imagery. This problem is often found in very high-spatial resolution images due to the per-pixel classification process used. In high-spatial resolution imagery this process takes into account pixels individually so that a land-cover object, e.g. residential block of land consists of several pixels with different spectral-related cover categories, as opposed to one homogeneous pixel in a larger image. To reduce this effect, a majority filtering technique was applied and an improved accuracy level of $87.05 \%$ was achieved. The derived spectral-related cover map at this accuracy level was accepted and used in the subsequent processes. Figure 5 shows the map of spectral-related cover dimension generated from the multispectral classification.

Information on spectral-related cover dimension may be considered as a generic land-cover map. Contents of this land-cover map are directly related to cover types that can be extracted using standard multispectral classification procedures. For example, studies dealing with urban heat island effects (Weng and Larsson, 2005) require generic information on land-cover as a basis for emissivity mapping. The map and classification scheme under spectral-related cover dimension may satisfy this need. In Indonesia and some (sub-)tropical developing countries, types of roof 


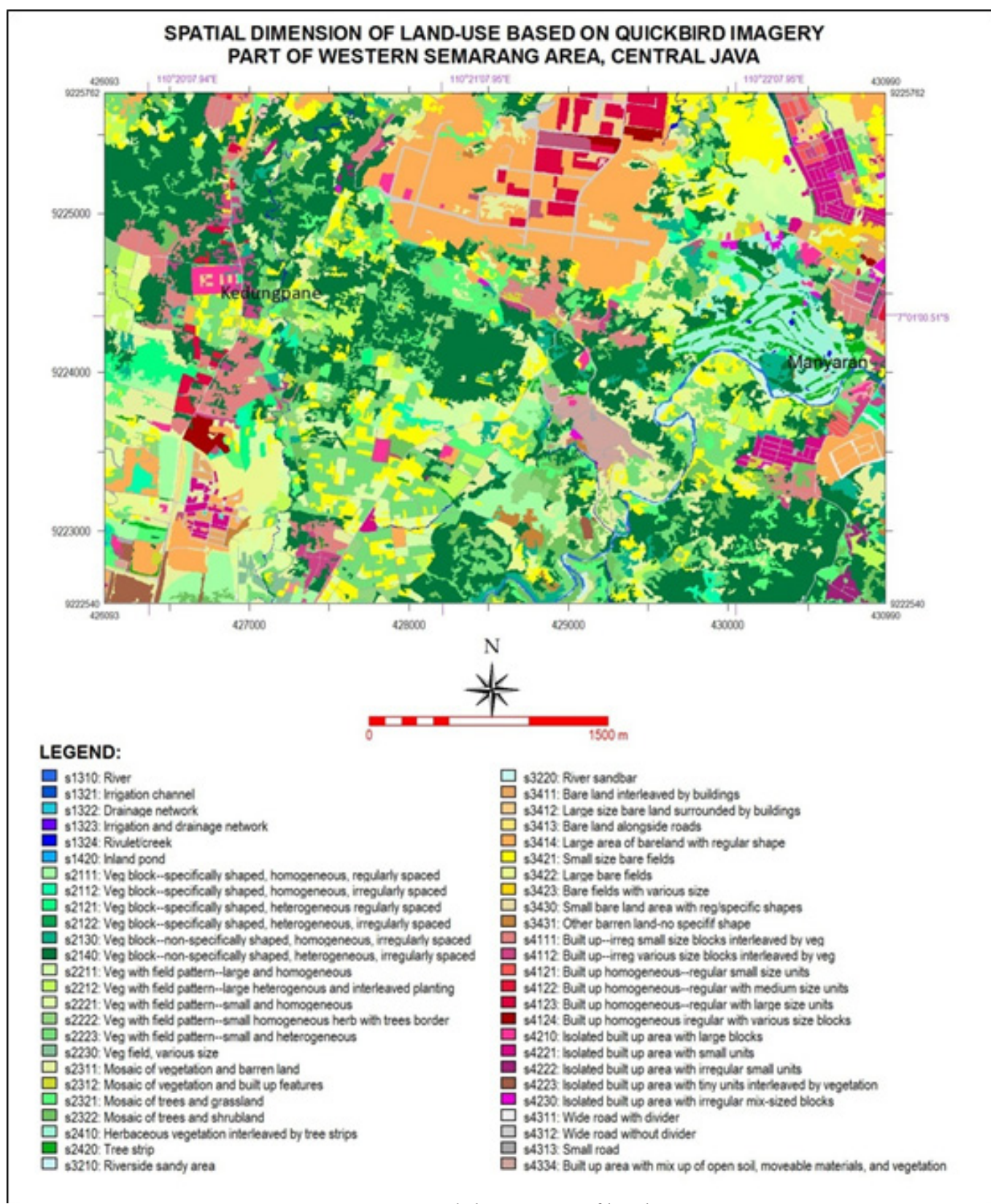

Figure 6. Spatial dimension of land-use.

tile are related to the settlement quality. Surveys on carbon stock of urban vegetation (Hutyra et al. (2011) may also make use of the categorisation of vegetation cover, supported by a vegetation index map if necessary.

\section{Map of Spatial Dimension}

Until now, information on spatial dimension of land-cover/land-use has been difficult to obtain using multispectral classification and moderate-spatial resolution data. Each category is defined by a set of criteria that is hard to incorporate simultaneously in current image processing systems. The criteria include: (a) location, (b) shape, and (c) specific pattern. Location can only be defined using visual approach, even though relative position, e.g. "adjacent to-", "contained in-", "in contact with-" may be defined using topological analyses in vector GIS. Figure 6 shows the result.
Accuracy assessment of the spatial dimension was not carried out because: (a) spatial pattern is easier to observe using vertical view than nearly horizontal field observation, and (b) the spatial resolution of Quickbird pan-sharpened colour composite image $(60 \mathrm{~cm})$ is fine enough for observing spatial details such as road divider, cars, and individual vegetation stands.

The use of OBIA in generating spatial dimension was less successful, compared to visual interpretation. The object-based classification of spatial dimension achieved $65.27 \%$ overall accuracy (Kappa $=0.5978)$. However, it is understandable that the categorisation for spatial dimension is too complicated to be used in such classification, since it includes many spatial parameters like shape, location, pattern/regularity, and sub-unit size (e.g. average building size) within each mapping unit. These parameters were not accommodated in the object-based segmentation and classification method 


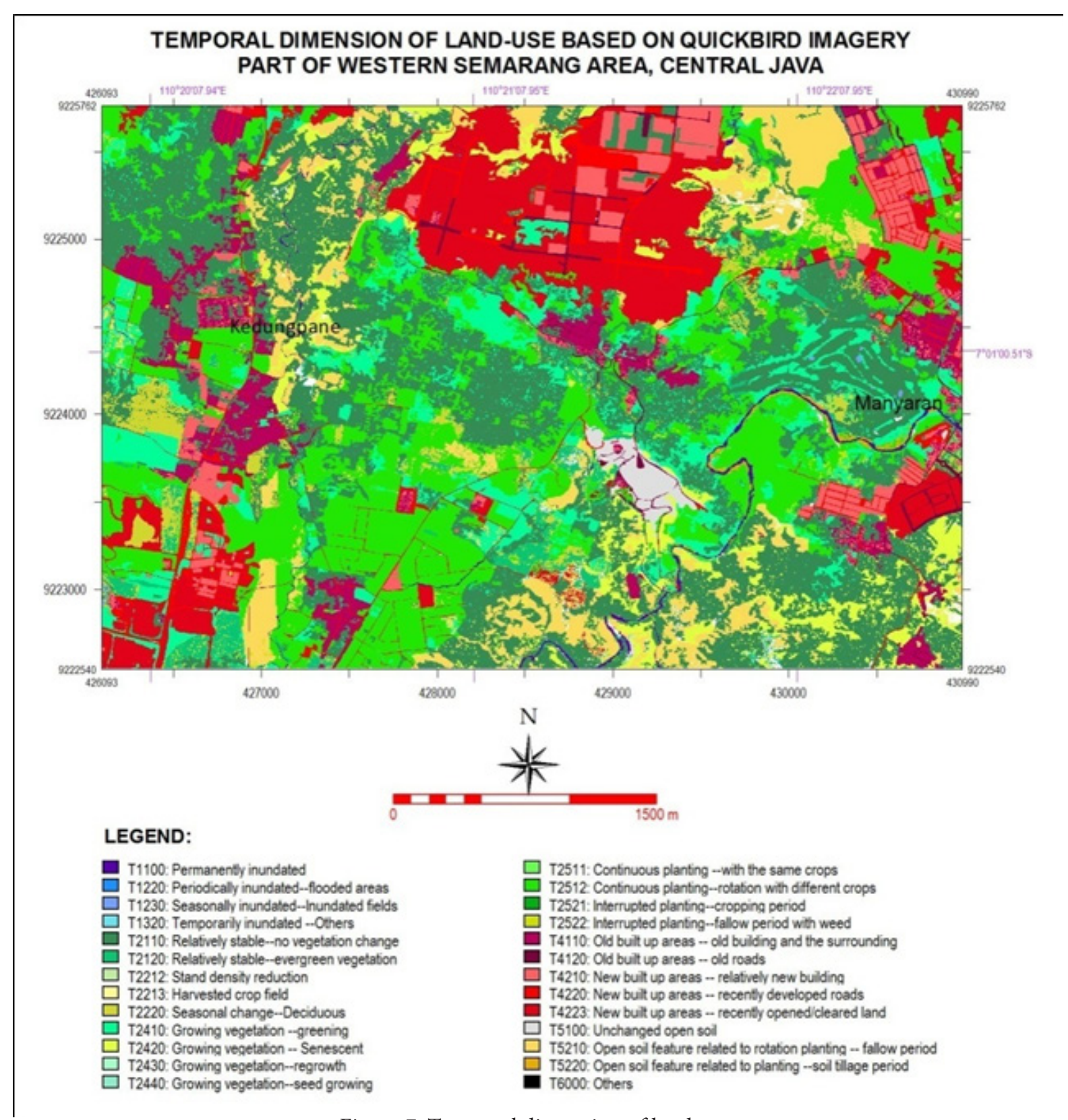

Figure 7. Temporal dimension of land-use

we used, since there was no functionalities relevant to those parameters.

\section{Map of Temporal Dimension}

Temporal dimension is rarely included as an attribute for classifying images. Normally it is used as additional information to define class membership. This dimension could be extracted from the image by taking into account the type, status, condition and spatial pattern of the land-cover at the time of recording (which are represented by the spectral-related cover and spatial dimensions), and the crop calendar elevation and slope steepness. Figure 7 depicts the temporal dimension of map.

In comparison to other dimensions, this map shows the least number of categories. The general pattern revealed on the map reflects similarity with other dimensions. Similar features in spatial or spectral dimensions presented differently in the temporal context. The main categories of temporal information are: (1) length of inundation-related features, (2) vegetation change-related features, (3) open soil change-related features, (4) development stage-related features. Under vegetation-change related features, subtler categories found in the study area were: (a) relatively stable/no change in vegetation cover, which is represented by evergreen vegetation, (b) growing vegetation, which is represented by greening and senescent vegetation, and (c) rotation planting represented by continuous planting (both with the same and with different crops) and interrupted planting (cropping and fallow periods). In the coastal lowland areas length of inundation-related features pattern indicates how frequent those areas were inundated, both naturally (due to tidal activities) and artificially 


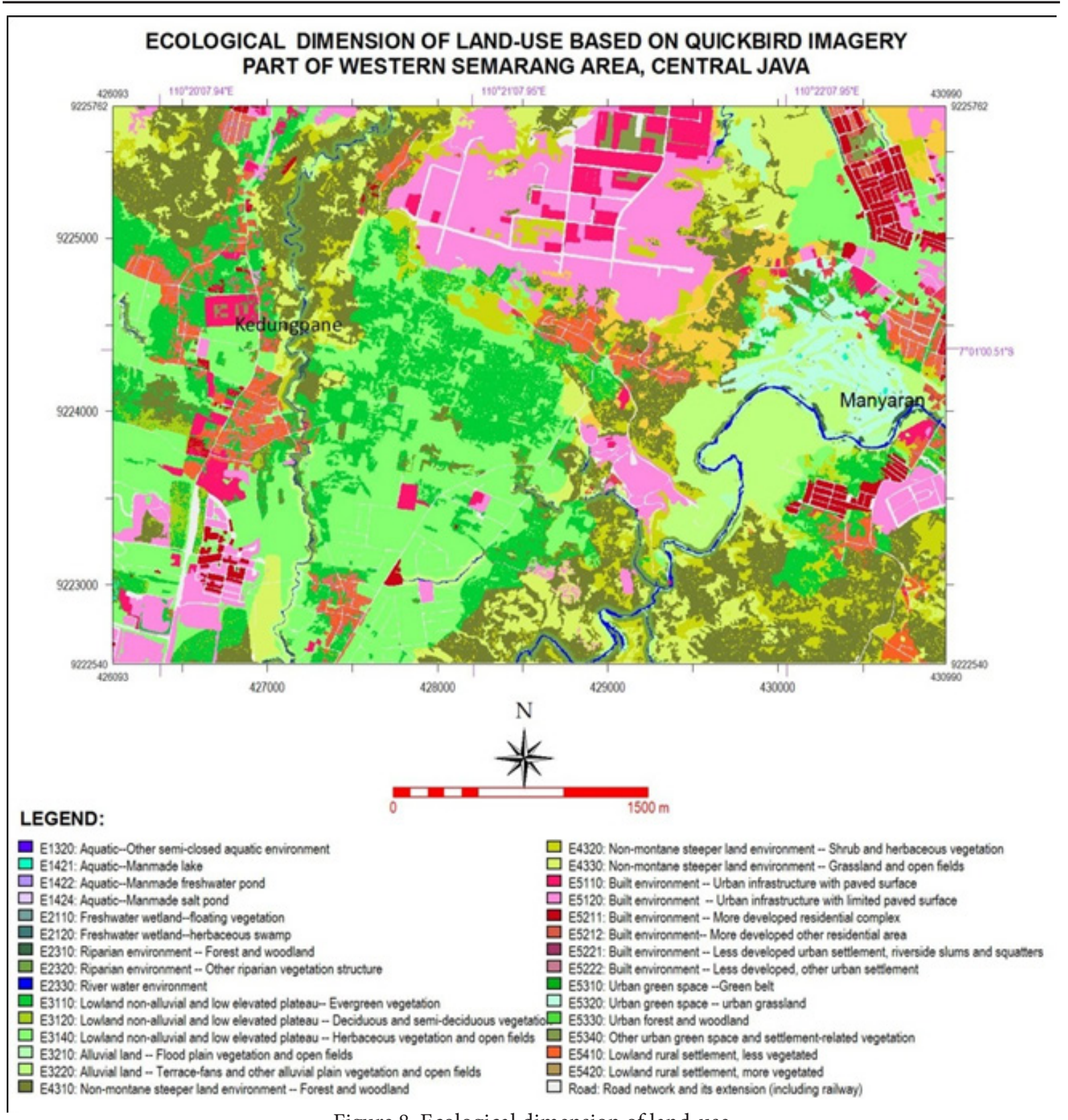

Figure 8. Ecological dimension of land-use

(due to irrigation process).

The temporal aspect of land-cover/land-use is rarely used as a descriptor of mapping unit in a consistent way. Occasionally, information on plant rotation comes up in agricultural land-use map or phenology is used to classify multitemporal data. Deciduous and evergreen are normally classified as vegetation types, not the temporal dimension of the vegetation. Growing stages are sometimes presented on the map for studies related to biomass estimates. Length of inundation is normally contained in hydrological-related phenomena, not in land-cover/land-use maps. The temporal dimension map in this study tries to include temporal characteristics of land-cover/land-use together in one map, so that any relevant information required may be extracted in a flexible way. Moreover, the presentation of temporal dimension in a separate layer can overcome problems related to conflicting requirement of a good classification scheme. Accuracy assessment of this map gave a relatively good result, i.e. $80.01 \%$ overall accuracy and Kappa index of 0.7784. The use of the spatial dimension map supported by a DEM-based terrain map contributed significantly to generating temporal information from single date imagery.

\section{Map of Ecological Dimension}

As shown on Figure 8, the ecological dimension map represents the distribution of mapping units related to ecological aspects of the land-cover/land-use. The main categories under this dimension are: (a) aquatic environment, (b) wetland and riverside environment, (c) lowland and alluvial land environment, (d) montane and steeper lands environment, and (e) 


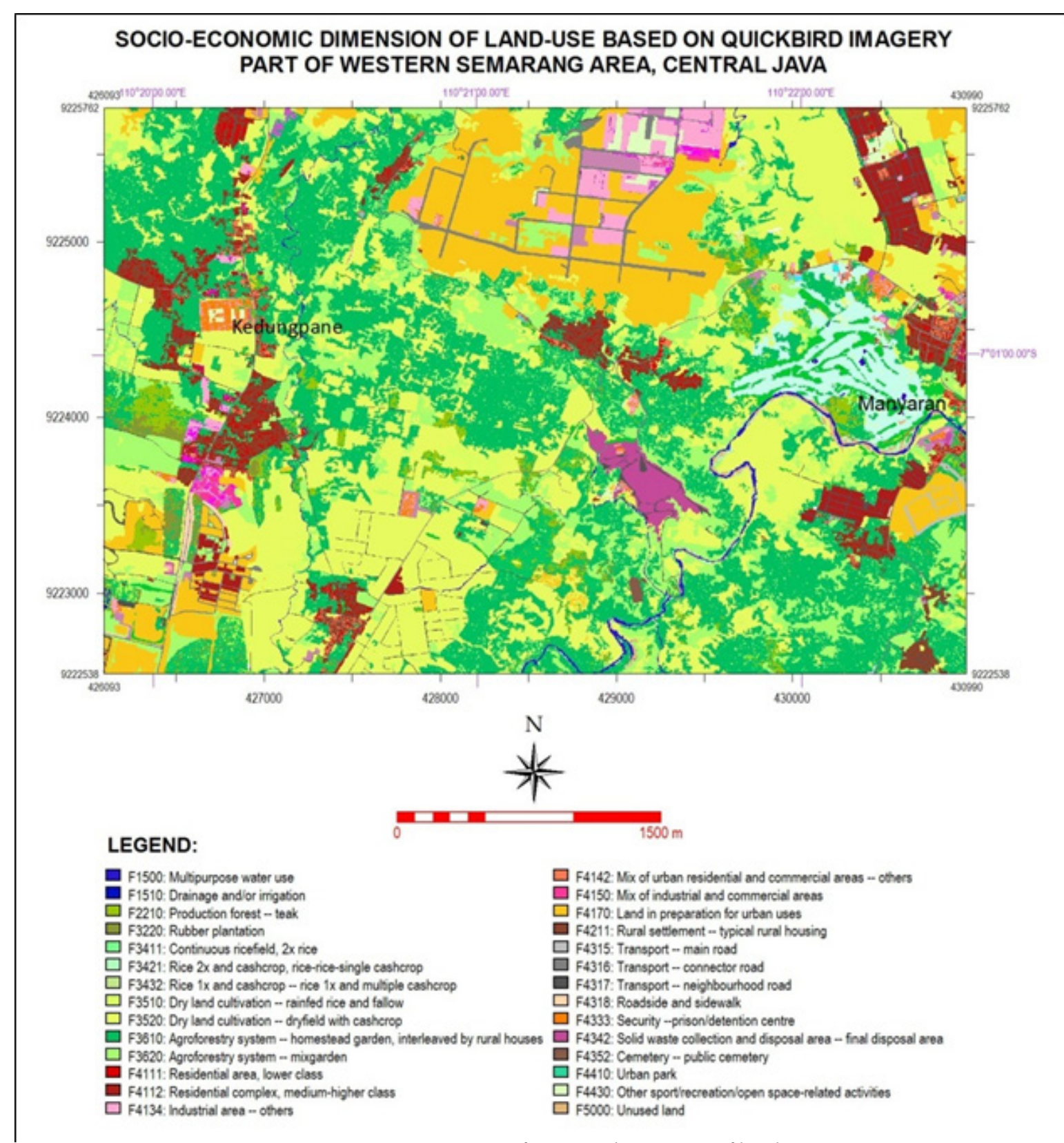

Figure 9. Sosio-economic function dimension of land-use

built environment. For example, under the built environment category, the following categories were be to be distinguished: (1) E5110/urban infrastructure with paved surface, (2) E5211/more developed residential complex, (3) E5221/less developed urban settlement, riverside slums and squatters, (4) E5320/urban grassland, and (5) E5340/other urban green space and settlement-related vegetation. Under the riverside and wetland environment category, the following mappable features were identified: (1) E2310/riparian forest and woodland, (2) E2330/river water environment.

Accuracy assessment of the ecological dimension map showed that a slightly lower accuracy level $(76.20 \%$ and Kappa index $=0.7424)$ as compared to that of temporal dimension map was achieved. Confusion between classes mainly occurred between E3120 (Lowland non-alluvial and low elevated plateau with deciduous vegetation) and E3140 (Lowland nonalluvial and low elevated plateau with herbaceous vegetation and open fields); as well as between E5221 (Built environment with less developed urban settlement, riverside slums and squatters) and other built environment classes. In the E3120-E3140 confusion, the inaccuracy was conveyed by the spectral-related cover map and propagated during map overlay. The use of multiple criteria for characterising E5221 class, i.e. regularity, roof tile type, location and block/unit size still mislead to other categories, since in old and densely populated urban settlement very accurate differentiation of urban settlement can only be done using field survey. This was not the case when the settlement (residential area) is relatively new, relatively isolated, or located in the urban fringe.

As the ecological units are closely related to 
the biophysical characteristics of the land-cover, the ecological dimension map also shows traces of the per-pixel classification result conveyed by the spectral-related cover dimension map. The rule-based classification process used for generating the ecological dimension map was mostly controlled by the spectralrelated cover classes, although the spatial dimension and terrain unit maps were also used.

On most maps showing land-cover/land-use features, ecological information normally mixed up with that of socio-economic functions. Maps of vegetation ecology or eco-floristic composition, for example, tried to accentuate the vegetation composition in relation with their terrain characteristics, e.g. climate, landforms, soils, slopes, and hydrology. Areas without (semi-)natural vegetation appearing on the map are frequently defined arbitrarily, regardless the inconsistence in categorisation and naming. Moreover, the level of details of those other categories are normally kept as general as possible, e.g. 'buildings', 'settlement', or 'agricultural lands'. In the ecological dimension map, all features are presented as ecological units, from both natural and human-influenced environmental perspectives. Therefore, studies on the leptospirosis in Bantul (Widayani et al. 2016) may be supported by this kind of map.

\section{Map of Socio-economic Function Dimension}

The map presented in Figure 9 shows full description of land-use. The socio-economic function was specified in four main categories: (a) water-based utilisation, (b) forest-based utilisation, (c) agricultural uses, and (d) settlement and infrastructures. Further categorisation details were then derived with respect to this major grouping.

For example, under the agricultural uses, several classes have been mapped: (a) F3221/other rubber estate, (b) F3411/rice field with twice planting, and F362/mixed garden. Besides the agricultural categories, under the settlement and infrastructures, the following classes have been specified: (a) F4112/residential complex, medium-higher class, (b) F4313/loading zone, and (e) F4352/public cemetery. Together with all other dimensions, the map of socio-economic function dimension can be displayed as a multilayer dataset (Figure 9), ready for spatial query using GIS.

Socio-economic function dimension expresses how people make use of the land to satisfy some of their needs. Theis dimension shows a consistent categorisation in terms of "uses". Moreover, this study also demonstrates that integration of image processing and GIS can derive relatively detailed land-use categories. Some classes also require additional information with administrative boundaries, which can only be supplied by secondary data, e.g. land status. Some others can easily be specified using spectral approach supported by limited ancillary data, e.g. pine (Pinus mercusii) production forest areas, since virtually all areas with pine trees are intended for production forest.

Accuracy assessment shows that an overall accuracy of $83.63 \%$ was achieved, with Kappa 0.8209 . Confusions were mainly constituted by continuous rice field with three times rice (F3411) and continuous rice field with twice rice (F3412), homestead garden (F3610) and forest garden (F3640) and mix garden (F3620). As compared to the ecological dimension map, the socioeconomic dimension map was less grainy, because the objects --instead of individual pixels-- played a significant role during rule-based classification. The spatial pattern defined in the spatial dimension map was closer to the function (use) of the cover types, while the biophysical classes as defined in the multispectral classification were closer to the ecological units.

The multidimensional or versatile land-use classification system also has both advantages and limitations. The following paragraphs discuss these briefly. Several advantages of the developed classification system are:

(a) Each dimension may be used separately if required, depending on the types of application;

(b) Any application related to land assessment and planning that requires mixed or combined landcover/land-use classification system may make use of the multidimensional land-use map, i.e. by using spatial query with respect to the accompanying classification schemes, so that there is no need to carry out land-cover/land-use mapping process separately or redundantly;

(c) It can be applied using remotely sensed imagery at various spatial scales. In this paper, examples using high-spatial resolution imagery has been demonstrated.

Conceptually, once the multidimensional or versatile land-use spatial dataset containing all dimensions is stored in a GIS environment, nearly any land-cover/land-use map with particular reference of existing classification system may be derived using spatial queries. Derivation of a map referring to other classification schemes may be done by developing a translation table showing relationship between classes or categories within the destination land-cover/landuse map and all categories under the versatile landuse classification system. The translation table may then be transformed to computer-based rules in a GIS environment. Since the relationship between categories can normally be one-to-one, one-to-many, or many-to-one, the multidimensional categories supply much more options of classes to be translated to the destination classification system. The translation may be undertaken by (a) renaming a class, or (b) combining two or more classes.

Several limitations of this study have been identified. These are related to the study area as the model, consistence of categorisation, and information 
extraction methods with remotely sensed image analyses and GIS. This study was carried out in a relatively small area. That is to say, the success of methods described previously should be reassessed using different dataset with different landscape characteristics. Another thing to consider is that land-use is a multifaceted concept, which cannot be modelled simply based on remotely sensed imagery, and merely using those five dimensions. In highly-modified or more developed regions like urban areas, land-use types are normally less correlated to external form of the features, e.g. building shape, density and pattern. The utilisation of imagery as a basis for modelling the land-use into multidimensional maps should be put in the context of complementary or alternative approach, where field surveys frequently fail to generate more comprehensive, efficient and rapidly provided information required in a planning process. In addition to these notes, four dimensions (spatial, temporal, ecological and socio-economic function) should be used in combination with field-based landuse survey and measurement, particularly for urban planning purposes.

Remote sensing normally delivers accurate results, as compared to the time, cost and efforts to access required. Indonesia is situated in a wet tropical region so that cloud cover and hazy atmosphere impede regular acquisition of good quality imagery at any day throughout a year. To overcome that problem, the increasing number of commercially available satellite systems with higher acquisition frequency and variable viewing angles capability (e.g. Sentinel, ALOS, WorldView, PlanetScope) might be used. The use of simple map overlays to generate other dimensions' maps needs to be improved in the next studies, e.g. by incorporating machine learning algorithms such as artificial neural network (Jensen, 2013) or support vector machine (Baghdadi and Zribi, 2016). The ecological and socio-economic function dimensions, for example, may be modelled using more sophisticated spatial analyses tools, e.g. neighbourhood analysis. In addition, the presence of particular socio-economic functions is sometimes related to their neighbours, so that analysis of adjacency or contiguity in vector data model needs to be explored, which can be combined with more advanced object-based image analysis approach (Blaschke et al., 2016; Lang and Tiede, 2016).

\section{Conclusions}

This study has shown that land-use is a multidimensional concept, which can be mapped using image-based analysis approaches. In order to derive land-use information to support local planning processes, all mappable dimensions that can be generated from remotely sensed imagery should be prepared. Each dimension is presented in a separate map layer, and all together should be stored in a versatile land-use information system dataset within GIS environment for flexible use and retrieval, depending on the need for relevant data. A standard image processing procedure, accompanied by visual interpretation and widely available raster GIS analytical tools can be used to develop the information system. However, advances in image processing and spatial data analyses give new opportunities for generating better results, so further studies should be explored.

\section{Acknowledgments}

The authors wish to thank the late Prof. Geoff MacDonald (CSIRO Sustainable Ecosystems/The University of Queensland, Australia), Prof. Stuart Phinn of the UQ's Remote Sensing Research Centre, and Dr. David Pullar of the UQ's School of Earth and Environmental Sciences for their valuable comments and suggestions on the basic ideas of this topic.

\section{References}

Anderson, J.R., Hardy, E., Roach, J. and Witmer, R. (1976). A Land-use and Land-cover Classification System for Use with Remote Sensor Data. Washington, DC: US Geological Survey Professional Paper 964.

Baghdadi, N., and Zribi, M. (2016).Optical Remote Sensing of Land Surfaces -- Techniques and Methods. London: ISTE Press Ltd

Blaschke, T., Kelly, M., and Merschdorf , H. (2016). Object-Based Image Analysis: Evolution, History, State of the Art, and Future Vision. In: Thenkabail, P.S. (ed.) Remote Sensing Handbook Volume I -- Remotely Sensed Data Characterization, Classification, and Accuracies. Boca Raton CRC Press.

Cord, A., Conrad, C. , Schmidt, M., and Dech, S. (2010). Standardized FAO-LCCS land cover mapping in heterogeneous tree savannas of West Africa. Journal of Arid Environments 74 (2010): pp 1083-1091.

Danoedoro, P. (2003). Multisource Classification for Land-use Mapping based on Spectral, Textural, and Terrain Information using Landsat Thematic Mapper Imagery: A Case Study of SemarangUngaran Area, Central Java. Indonesian Journal of Geography (52):2. pp 81-106.

Danoedoro, P., Phinn, S., and McDonald, G. (2004). Developing a Versatile Land-use Information System based on Satellite Imagery for Local Planning in Indonesia Phase I: Establishment of Classification Scheme. Proceedings. 7th International Seminar on GIS for Developing Countries (GISDECO-7)“GIS Capacity Building and Infrastructure”, Universiti Teknologi Malaysia, Skudai, Johor, pp 10-12

Danoedoro, P., and Phinn, S. (2005). Detailed Landcover Mapping by Introducing Higher-spatial Resolution panchromatic Bands in Multispectral Classification: Examples using Landsat ETM+ and Quickbird Imagery. Proceedings, MapAsia 
2005 Conference: Empowering People Through Geospatial Information, Jakarta 22-25 August 2005.

Danoedoro, P. (2006). Extracting Land-Use Information Related to Socio-Economic Function from Quickbird Imagery: A Case Study Of Semarang Area, Indonesia. Proceedings of the Map Asia Conference, Bangkok

Danoedoro, P. (2007). Versatile Land-use Information for Local Planning in Indonesia: Contents, Extraction Methods and Integration based on Moderate-and High-spatial Resolution Imagery. PhD thesis, The University of Queensland, StLucia, Australia.

Danoedoro, P. (2015). Pengaruh Jumlah dan Metode Pengambilan Titik Sampel Penguji Terhadap Tingkat Akurasi Klasifikasi Citra Digital Penginderaan Jauh. Prosiding. Simposium Sains Geoinformasi ke-4, 27-28 Oktober 2015 di Yogyakarta

Eastman, J. R. (2016). TerrSet Tutorial. Worchester, MA: Clark University

Ehlers, M., Gahler, M., and Janowsky, R. (2003). Automated Analysis of Ultrahigh Resolution Remote Sensing Data for Biotope Type Mapping: New Possibilities and Challenges. ISPRS Journal of Photogrammetry and Remote Sensing, 1252, pp 1-12.

Feng, C.C., and , Flewelling, D.M. (2004). Assessment of Semantic Similarity between Land Use/Land Cover Classification Systems Feature Based Approach, Relative Importance Approach. Computers, Environment and Urban Systems 28 (2004): pp 229-246.

Feranec, J., Solin, L., Kopecka, M., Otahel, J., Kupkova, L., Stych, P., Bicik, I., Kolar, J., Cerba, O., Soukup, T., and Brodsky, L. (2014). Analysis and Expert Assessment of the Semantic Similarity Between Land Cover Classes. Progress in Physical Geography (38) 3: pp 301-327.

Hansen, M.C., Potapov, P.V., Moore, R., Hancher, M., and Turubanova, S.A., Tyukavina, A., Thau, D., Stehman, S.V., Goetz, S.J., Loveland, T.R., and others, (2013). High-Resolution Global Maps of 21st -Century Forest Cover Change. Science. 342(6160): pp 850-853.

Hengl, T. (2017). Current global land cover maps. Available at

http://worldgrids.org/doku.php/wiki:land_cover_and_ land_use. Accessed on Friday 28 April 2017.

Hutyra, L.R., Yoon, B., and Alberti, M. (2011). Terrestrial Carbon Stocks Across a Gradient of Urbanization: A Study of the Seattle, WA Region. Global Change Biology 17, pp 783-797.

Janssen, L.J.M., and Di Gregorio, A. (2003). Land-use Data Collection using "Land Cover Classification System": Results from a case Study in Kenya. Land Use Policy 20: pp 131-148.

Jensen, J. R. (2013). Remote Sensing of the Environment:
An Earth Resource Perspective. 3nd edition. Englewood Cliffs, N.J.: Prentice Hall.

Kallimanis, A.S., and Koutsias, N. (2013). Geographical Patterns of Corine Land Cover Diversity Across Europe: The Effect of Grain Size and Thematic Resolution. Progress in Physical Geography 37(2): pp 161-177.

Kindu, M., Schneider, T., Teketay, D., and Knoke, T. (2013). Land Use/Land Cover Change Analysis Using Object-Based Classification Approach in Munessa-Shashemene Landscape of the Ethiopian Highlands. Remote Sensing. (2013) 5: pp 2411-2435.

Kosmidou, V., Petrou, Z., Bunce, R.G.H., Mücher, C.A., Jongman, R.H.G , Bogers, M.M.B., Lucas, R.M., Tomaselli, V., Blonda, P., Padoa-Schioppa, E., Manakos, I., and Petrou, M. (2014). Harmonization of the Land Cover Classification System (LCCS) with the General Habitat Categories (GHC) classification system. Ecological Indicators 36 (2014) pp 290- 300.

Lang, S. And Tiede, D. (2016). Geospatial Data Integration in OBIA: Implications of Accuracy and Validity. In: Thenkabail, P.S. (ed.) Remote Sensing Handbook Volume I -- Remotely Sensed Data Characterization, Classification, and Accuracies. Boca Raton CRC Press.

Latham, J., Cumani, R., Rosati, I., Bloise, M. (2014). Global Land Cover SHARE (GLC-SHARE) database. Beta-Release Version 1.0. FAO, Rome.

Lee, S., Hwang, S., Lee, S., Hwang, H., and Sung, H. (2009). Landscape Ecological Approach to The Relationships of Land Use Patterns in Watersheds to Water Quality Characteristics. Landscape and Urban Planning (92) (2009): pp 80-89.

Lillesand, T.M., Kiefer, R.W., and Chipman, J. (2014). Remote Sensing and Image Interpretation (6th ed.). New York: Wiley and Sons

Loveland, T.R. and Belward, A.S. (1997) The International Geosphere Biosphere Programme Data and Information System Global Land Cover Data Set (DISCover). Acta Astronautica (Vol 41), 4-10, pp 681-689.

Martínez, S. and Mollicone, S. (2012). From Land Cover to Land Use: A Methodology to Assess Land Use from Remote Sensing Data. Remote Sensing. (2012) 4: pp 1024-1045.

McCallum, I., Obersteiner, M., Nilsson, S., and Shvidenko, A. (2010) A Spatial Comparison of Four Satellite Derived $1 \mathrm{Km}$ Global Land Cover Datasets. International Journal of Applied Earth Observation and Geoinformation, 8, pp 246-255.

Moreno, A.J.P, and De Larriva, E.M. (2012). Comparison between New Digital Image Classification Methods and Traditional Methods for Land-cover Mapping. In: Giri, C.P. (ed) Remote Sensing of Land-use and Land-cover. Principles and Applications. New York: CRC Press.

Moskal, L.M., Styers, D.M. and Halabisky, M. (2011) 
Monitoring Urban Tree Cover Using Object-Based Image Analysis and Public Domain Remotely Sensed Data. Remote Sensing, 3, pp 2243-2262.

Osborne, P.I. (1999). Tropical Ecosystems and Ecological Concepts. Cambridge: Cambridge University Press

Oppelt, N., Scheiber, R., Gege, P. Wegmann, M., Taubenboeck, H., Berger, M. (2016). Fundamentals of Remote Sensing for Terrestrial Applications: Evolution, Current State of the Art, and Future Possibilities. In: Thenkabail, P.S. (ed.) Remote Sensing Handbook Volume I -- Remotely Sensed Data Characterization, Classification, and Accuracies. Boca Raton CRC Press.

Perlman, D.L., and Milder, J.C., (2005). Practical Ecology for Planners, Developers and Citizens. Washington: Island Press

Pu, R., Landry, S., and Yu, Q. (2011). Object-based Urban Detailed Land-cover Classification with High-spatial Resolution IKONOS imagery. International Journal of Remote Sensing, 32 (12), pp 3285-3308

Puissant, A., Hirsch, J., and Weber, C. (2005). The Utility of Texture Analysis to Improve Per-pixel Classification for High to Very High Spatial Resolution Imagery. International Journal of Remote Sensing 26(4): pp 733-745.

Sulistyo, B., Gunawan, T., Hartono, Danoedoro, P. And Listyaningrum. N. (2017). Absolute Accuracy of the Erosion Model of DEM-NDVI and it's Modification. International Journal of Geoinformatics (13) 2, pp 23-34.

Szuster, B.W. Chen, Q., and Borger, M. (2011). A Comparison of Classification Techniques to Support Land Cover and Land Use Analysis in Tropical Coastal Zones. Applied Geography 31 (2011): pp 525-532.

Tarantino, C., Lovergine, F.P., Adamo, M. and Pasquariello, G. (2011). Contextual Information for the Classification of High Resolution Remotely Sensed Images. Italian Journal of Remote Sensing 43 (2): pp 31-40.
Tchuente, A.T.K., Roujean, J-L. and Faroux, S. (2010). ECOCLIMAP-II: An Ecosystem Classification and Land Surface Parameters Database of Western Africa at $1 \mathrm{~km}$ Resolution for the African Monsoon Multidisciplinary Analysis (AMMA) project. Remote Sensing of Environment 114 (2010) pp 961976.

Tobler, W. (1988). Resolution, Resampling and All That. In H. Mounsey and R. Tomlinson (eds) Building Database for Global Science. New York: Taylor and Francis

van der Ploeg , J.D., Laurent, C., Blondeau, F., and Bonnafous, P. (2009). Farm Diversity, Classification Schemes and Multifunctionality. Journal of Environmental Management 90 (2009): pp 124-131.

van Gils, H., Huizing, H., Kannegieter, A., \& van der Zee, D. (1991). The Evolution of the ITC System of Rural Land use and Land cover Classification (LUCC). ITC Journal (3): pp 163-167.

van Zuidam and van Zuidam Cancelado (1983). Terrain Analysis and Evaluation using Airphoto Interpretation - A Geomorphological Approach. Enschede: ITC

Weng and Larsson (2005). Satellite Remote Sensing of Urban Heat Islands: Current Practice and Prospects. In Jensen, R.R., Gatrell, J.D., and McLean D.D. (Eds) Geospatial Technologies in Urban Environments. Berlin: Springer-Verlag

Widayani, P., Gunawan, T. Danoedoro, P. and Mardihusodo, S.Y. (2016). Application of Geographically Weighted Regression for Vulnerable Area Mapping of Leptospirosis in Bantul District. Indonesian Journal of Geography (48) 2: pp 168- 177

Young, A. (1998). Land Resources: Now and for the Future. Cambridge: Cambridge University.

Zhang, R., and Zhu, D. (2011). Study of land cover classification based on knowledge rules using highresolution remote sensing images. Expert Systems with Applications 38 (2011): pp 3647-3652. 